Review

\title{
New Tools for Molecular Therapy of Hepatocellular Carcinoma
}

\author{
Alessandra Marchetti ${ }^{1, *}$, Francesca Bisceglia ${ }^{1}$, Angela M. Cozzolino ${ }^{1}$ and Marco Tripodi ${ }^{1,2, *}$ \\ 1 Department of Cellular Biotechnologies and Hematology, Pasteur Institute-Cenci Bolognetti \\ Foundation, Sapienza University of Rome, Viale Regina Elena, 324, 00161 Rome, Italy; \\ E-Mails: bisceglia@bce.uniroma1.it (F.B.); cozzolino@bce.uniroma1.it (A.M.C.) \\ 2 National Institute for Infectious Diseases Lazzaro Spallanzani, IRCCS, Via Portuense, 292, 00149 \\ Rome, Italy \\ * Authors to whom correspondence should be addressed; E-Mails: marchetti@bce.uniroma1.it (A.M.); \\ tripodi@bce.uniroma1.it (M.T.); Tel.: +39-6-49918244; Fax: +39-6-44252865.
}

Academic Editor: Stephen L. Chan

Received: 15 September 2015 / Accepted: 22 October 2015 / Published: 30 October 2015

\begin{abstract}
Hepatocellular carcinoma (HCC) is the most common type of liver cancer, arising from neoplastic transformation of hepatocytes or liver precursor/stem cells. HCC is often associated with pre-existing chronic liver pathologies of different origin (mainly subsequent to HBV and HCV infections), such as fibrosis or cirrhosis. Current therapies are essentially still ineffective, due both to the tumor heterogeneity and the frequent late diagnosis, making necessary the creation of new therapeutic strategies to inhibit tumor onset and progression and improve the survival of patients. A promising strategy for treatment of HCC is the targeted molecular therapy based on the restoration of tumor suppressor proteins lost during neoplastic transformation. In particular, the delivery of master genes of epithelial/hepatocyte differentiation, able to trigger an extensive reprogramming of gene expression, could allow the induction of an efficient antitumor response through the simultaneous adjustment of multiple genetic/epigenetic alterations contributing to tumor development. Here, we report recent literature data supporting the use of members of the liver enriched transcription factor (LETF) family, in particular HNF4 $\alpha$, as tools for gene therapy of HCC.
\end{abstract}

Keywords: HCC; HNF4 $\alpha$; LETFs; miRNAs; TGF $\beta$; EMT; gene therapy 


\section{Introduction}

Hepatocellular carcinoma (HCC) is one of the most common cancers worldwide and the most frequent among the primary tumors of the liver. HCCs are phenotypically and genetically heterogeneous tumors, since they often develop on the pathological background of pre-existing chronic liver diseases, including fibrosis or cirrhosis in consequence of $\mathrm{HBV}$ and $\mathrm{HCV}$ infections, alcoholic injury, or autoimmune hepatitis, that impair organ function and reduce the efficacy of common cancer therapies [1]. Moreover, most HCC patients are diagnosed at advanced stages of disease when the high tumor recurrence rate and the tendency to metastasize make current treatments ineffective and the prognosis poor [2].

In recent years, intense pre-clinical and clinical research have been devoted to the development of tailored therapeutic molecules, capable of restoring the physiological cell functions lost in transformed hepatocytes, through the gene therapy of HCCs. Gene therapy is a promising approach, since it is possible to deliver vectors directly into hepatic tumors, reducing potential side effects derived from transduction in non-target cells. Molecules utilized in current protocols include genes for proteins or microRNAs (miRNAs) displaying antitumor properties (anti-proliferative, pro-apoptotic, anti-angiogenic, or immunomodulatory).

Unfortunately, highly effective results have not been obtained so far, due to the low efficiency of the gene transfer [3] and to the genetic heterogeneity of HCCs [4]. For this reason, the most promising candidates would be oncosuppressor genes able to induce an efficient antitumor response without a specific correction of multiple mutations contributing to tumor development (e.g., p53) or differentiation-specific master genes, able to act as reprogramming transcriptional factors, coordinating extensive gene expression. In the context of the latter strategy, we will discuss recent progress in the knowledge of HCC biology and genetics supporting the use of Liver Enriched Transcription Factors (LETFs), and in particular of hepatocyte nuclear factor $4 \alpha(\mathrm{HNF} 4 \alpha)$, as promising candidates for targeted gene therapy of HCCs.

\section{Molecular Alterations in HCC}

\subsection{Cell-Autonomous Changes}

In spite of the heterogeneity of $\mathrm{HCC}$, tumor onset and progression have been associated with recurring cell-autonomous molecular changes [5] such as the loss of expression of differentiation genes (e.g., Hepatocyte Nuclear Factor 1 and 4, HNF1 $\alpha$, and HNF4 $\alpha$ ) [6,7], chromosomal instability leading either to the loss of heterozygosity in tumor suppressor genes (e.g., p. 53) [8] or to the amplification of loci for oncogenes (e.g., ERK5) [9], and aberrant activation of signaling pathways (e.g., Wnt/ $\beta$-catenin pathway) [10].

In addition, recent findings highlight how epigenetic alterations are commonly observed in human HCCs [11,12] and can be exploited as clinical predictors for diagnosis and prognosis [13]. These alterations include aberrant methylation of tumor suppressor genes [13], post-translational histone modifications [14,15], and altered expression profile of miRNAs [16,17].

The progression of HCC toward more aggressive stages, responsible for the worst prognosis in patients, is frequently associated to the activation, in transformed hepatocytes, of a transdifferentiation process: the epithelial-to-mesenchymal transition (EMT). EMT contributes to tumor progression through 
the loss of epithelial/hepatocyte cell differentiation, the acquisition of motility/invasivity properties and cancer stem cell traits, the resistance to apoptosis, and metastasis (reviewed in [18]). Overexpression of EMT markers (i.e., Snail and Twist) has been reported in invasive areas of primary tumors [19] and in metastasis of aggressive hepatocarcinomas [20], and were associated with poor prognosis. Their analysis in circulating tumor cells has been recently proposed as prognostic tools for HCC patients [21]. The role of EMT master genes, in particular Snail, in tumor progression was found to be mediated by (i) the direct transcriptional repression of an extensive amount of target genes involved both in epithelial (e.g., E-cadherin) [22] and hepatic (e.g., HNF4 $\alpha$ ) [23] differentiation, (ii) the increase of mesenchymal gene expression [23], and iii) the miRNA-mediated up-regulation of stemness genes [24]. The acquisition of EMT-related stem cell characteristics has been demonstrated to positively correlate with HCC progression [25]. The presence of stemness traits in HCC tumor cells, indeed, has been associated with chemoresistance and tumor recurrence after surgery [26,27] and can contribute to the intratumoral heterogeneity of HCC tumor cells [28].

\subsection{Non-Cell-Autonomous Cues}

An important role in HCC is also played by non-cell-autonomous cues, such as the presence of factors in the tumor niche promoting tumor growth or influencing proliferation/activation of tumor-associated fibroblasts [29,30].

In particular, the role of TGF $\beta$ cytokine in the progression of HCC was largely described. In HCC patients elevated plasma levels of TGF $\beta$ have been reported, correlating with poor prognosis $[31,32]$. Furthermore, in late stage HCC, the TGF $\beta$ signaling pathway is constitutively activated [33] and is involved in promoting tumor invasion through stimulation of vascularization [34], acquisition of stem-like features [35], and induction of EMT [36]. The molecular signature of late stage HCC-derived cell lines, indeed, showed high levels of EMT markers (including matrix metalloproteases, vimentin and, particularly, Snail) and down-regulation of genes for liver-specific functions, indicating a reduced hepatocyte/epithelial differentiation state [37]. TGF $\beta$ signaling, moreover, can be amplified in HBV-infected HCC cells by HBx protein [38].

TGF $\beta$ signaling is also closely linked to liver diseases favoring development of HCC. TGF $\beta$ can activate hepatic stellate cells (HSCs) [39] and induce an immune response, causing fibrosis and leading to HCC onset [40]. Its serum levels are also associated to virus-induced fibrosis [41,42]. Furthermore, TGF $\beta$ can induce production of CTGF (Connective Tissue Growth Factor) by cancer-associated fibroblasts promoting tumor progression [43].

Recent reports highlighted a role of biophysical changes in extra-cellular matrix stiffness as microenvironmental cues influencing tumor growth and progression. Fibro-cirrhotic livers, for example, are characterized by a significant increase of ECM stiffness [44]. YAP/TAZ were recently identified as molecular relay of mechanical stimuli exerted by ECM stiffness, inhibited by the Hippo signaling pathway and involved in organ size control [45]. Dysregulation of the Hippo/YAP cascade has been recently reported for several human tumors, including $\mathrm{HCC}$, and correlates with increased cell proliferation and survival, acquisition of stemness properties, and metastasis (reviewed in [46]). In particular, YAP overexpression was found in human HCC samples [47,48] and correlates with poor prognosis of HCC patients [49]. Furthermore, its inhibition in cells from advanced HCC restores 
hepatocyte differentiation inducing the up-regulation of master factors (i.e., HNF4 $\alpha / \mathrm{FOXA1/FOXA3)} \mathrm{and}$ leading to tumor regression [50]. Interestingly, YAP protein is directly involved in switching occupancy of HNF4 $\alpha$ on embryonic hepatoblast genes to adult hepatocyte genes [51], suggesting a direct role of YAP in influencing the function of key transcriptional factors and master genes of hepatocyte differentiation.

\section{Gene Therapy of HCC: Is It a Good Deal?}

As highlighted above, current therapies for $\mathrm{HCC}$ are still ineffective. Surgical liver resection efficiency is limited to small localized tumors with low risk of recurrence in non-cirrhotic patients. Conventional chemotherapy is largely unsuccessful due to tumor cell resistance and side effects of "non-selective" cytotoxic drugs. Furthermore, the immunosuppression associated to HCC (mainly subsequent to chronic $\mathrm{HBV}$ and $\mathrm{HCV}$ infections) negatively impacts on tumor recurrence. For this reason, immuno-based therapies have been proposed to ameliorate the clinical outcome of HCC patients (reviewed in [52]).

Targeted approaches have also been applied, in particular for advance-stage and unresectable HCC. These treatments include oral administration of the multikinase inhibitor sorafenib, or single target agents, such as gefitinib and erlotinib, currently involved in ongoing clinical trials in the US and EU [53]. The therapy with sorafenib, in particular, showed prolonged median overall survival and delayed the median time to progression in patients with HCC, showing limited and manageable adverse effects [54]. However, chronic liver diseases that usually underlie HCC may enhance the hepatotoxicity of these agents; accordingly, the prognosis of late-stage HCC patients is still poor [53].

In this context, the targeted gene therapy for the management of $\mathrm{HCC}$ seems to be the most promising approach. In particular, the adenoviral mediated gene therapy is well documented and included in several human clinical trials where the tolerance is high and side effects acceptable in most of the cases (reviewed in [55]). However, the efficiency of transduction and the tumor specificity still remain limiting factors for this approach. In HCC, these problems could be overcome by intratumoral administration of vectors and/or by the use of tumor-specific promoters that may restrict the delivery to hepatocytes (e.g., AFP) [56], especially improving efficacy and minimizing the toxicity of this therapeutical strategy.

Among different approaches of gene therapy (restoration of oncosuppressors, delivery of suicide genes, or inhibition of oncogenes) the delivery of "differentiating" factors could achieve the best results in terms of low toxicity and maintenance of tissue homeostasis, especially compared to killing drugs or agents inducing apoptosis. The most severe consequence may be related to the damage of the stem cell compartment with the decreased number of cells (stem cells or progenitors) responsible for tissue renewal. However, in the liver, the real involvement of resident liver stem/precursor cells in hepatic regeneration after chronic injury is strongly debated since it has been recently formally proved that adult hepatocytes originate from self-duplication of other hepatocytes rather than from stem cell differentiation [57,58]. Altogether, this knowledge suggests that the ectopic expression of differentiation master genes in the liver could be tolerated and the side effects reduced. 


\section{LETFs as Molecular Tools for Gene Therapy of HCC}

Maintenance of hepatocyte differentiation and control of liver-specific gene expression are attributed in large part to hepatocyte nuclear factors (HNFs) belonging to the LETF family, including HNF1 $\alpha$, HNF4 $\alpha$, HNF6, and FOXA2 [59]. Being reciprocal transcriptional activators, they operate cooperatively in a connected network in the liver, regulating several developmental and metabolic functions in hepatocytes $[60,61]$.

\section{1. $H N F 4 \alpha$}

The nuclear receptor $\mathrm{HNF} 4 \alpha$ is a key regulator of hepatocyte differentiation during embryonic development $[62,63]$, influencing the expression of other hepatic transcription factors, and stabilizing co-regulatory networks for the maintenance of a differentiated phenotype [61]. In the adult liver, HNF4 $\alpha$ is highly expressed in hepatocytes. HNF4 $\alpha$ maintains hepatocyte identity both by inducing epithelial/hepatic differentiation through a direct regulation of epithelial and metabolic target genes [62,64], and by actively inhibiting mesenchymal differentiation program through a direct repression of mesenchymal and EMT master genes [65]. Accordingly, experimental HNF4 $\alpha$ deletion in adult mouse livers has been shown to lead to dedifferentiation and proliferation of hepatocytes, hepatomegaly, and expansion of precursor cells (i.e., oval cells) [66,67].

HNF4 $\alpha$ is a strong inducer of mesenchymal-to-epithelial transition (MET). Its ectopic expression in fibroblast [62] and F9 cells [68] is sufficient to trigger epithelial gene expression and acquisition of epithelial polarity. Furthermore, HNF4 $\alpha$, together with FOXA1, FOXA2, or FOXA3, was found capable of inducing the direct reprogramming of mouse fibroblasts into hepatocyte-like cells [69].

Importantly, in addition to the transcriptional regulation of mRNAs, HNF $4 \alpha$ regulates the expression of miRNAs which, in turn, can act as pleiotropic elements influencing differentiation, EMT, stemness, and hepatocarcinogenesis.

In particular, HNF4 $\alpha$ (as well as other LETFs) was found to directly regulate expression of the liver-specific microRNA-122 (miR-122) [70], the most abundant miRNA in hepatocytes, and the first miRNA suggested as a tumor suppressor in the liver. Its expression, indeed, is frequently reduced in HCCs [71] and is associated with low differentiation, migration/invasivity of HCC cells [72,73], and poor prognosis in patients [72]. Mir-122 restoration in HCC cells leads to a reduction of mesenchymal markers [74], cell-cycle arrest or apoptosis [75], and sensitizes cells to antitumor agents [76,77]. Notably, miRNA-122 delivery in HCC murine models impaired tumor occurrence, growth, and progression [73,78].

Recently, the transcriptional regulation of other miRNAs, i.e., members of the miR-200 family and miR-34a, by HNF4 $\alpha$ has been described and showed to contribute to the active repression of stem cell genes [24]. Both miR-200 family members and miR-34a were suggested to function as tumor suppressors in HCCs. They appeared markedly down-regulated in HCC $[79,80]$ and their restoration in various cancer stem cells is associated with the loss of stem cell traits, inhibition of EMT, cell differentiation, and decreased motility/invasivity $[24,81,82]$. However, the role of miR-34a in cancer is currently debated [83] and, in HCC, has been related to the cellular context [84].

It has been recently shown that HNF4 $\alpha$ controls the epigenetic state of differentiated hepatocytes through the miR-29-mediated DNMT3A,B down-regulation [85]. Interestingly, low levels of miR-29 
and DNMT3A,B up-regulation correlate with TGF $\beta$-induced EMT, liver fibrosis, and aggressiveness of HCC [86-88]. Being the epigenetic changes, including DNA methylation, sustained by the presence of high levels of DNMTs, involved in both EMT [89] and hepatocarcinogenesis [90], miR-29 could represent a good target for a therapeutic approach aimed at the epigenetic reprogramming of HCC cells.

Several lines of evidence indicate HNF4 $\alpha$ as a potential tumor suppressor of HCC. In mature hepatocytes, loss/inactivation of its function resulted in an increased risk for development of HCC. Transient inhibition of HNF4 $\alpha$ is sufficient to initiate hepatocellular transformation in non-transformed hepatocytes and to increase invasiveness in transformed HCC cell lines through a microRNA-mediated inflammatory loop circuit [91]. This network can also contribute to the maintenance of HNF4 $\alpha$ inactivation during hepatocellular transformation [91]. Several studies have shown a decreased expression of HNF4 $\alpha$ in both murine models and human samples of HCC, thus indicating a critical role of this protein in the HCC onset/progression [7,92,93]. As a consequence, the restoration of HNF4 $\alpha$ expression/function in HCCs has represented, in the last few years, an important goal for molecular approaches to HCC treatment. The whole described tumor-suppressing functions of HNF4 $\alpha$ indicate that this protein represents a good candidate for the extensive reprogramming of tumor cells and, therefore, a promising tool for gene therapy of HCC.

Several data substantiate this expectation. Forced HNF4 $\alpha$ expression in dedifferentiated and aggressive HCC is sufficient to reduce tumor cell motility/invasivity by inducing differentiation and EMT inhibition [65,92]. Moreover, HNF4 $\alpha$ overexpression attenuates hepatic fibrosis and, in fibrotic livers, can prevent HCC occurrence by blocking the activation of myofibroblasts [93,94]. Furthermore, overexpression of HNF4 $\alpha$ in rodent HCC models blocks carcinogenesis and metastasis [93,95].

Overall, the restoration of the HNF $4 \alpha$ functions in invasive HCCs has been proven to be an efficient approach for the gene therapy of HCC, at least in experimental models. However, recent data have shown how microenvironment cues could reduce the efficacy of this approach. In particular, the presence of TGF $\beta$ in the tumor niche impaired HNF4 $\alpha$ activity by inducing the displacement of the ectopic protein from its target gene promoters through the inactivation of GSK-3 $\beta$ activity [96]. This result suggests the need to obtain improved HNF4 $\alpha$ proteins as tools for gene therapy, through the design of TGF $\beta$-insensitive mutants.

At the same time, the potential tumor suppressor activity of other members of the LETF family should be explored. Recently, the role in tumor suppression of HNF1 $\alpha$ and HNF6, has been described. Similarly to $\mathrm{HNF} 4 \alpha$, indeed, these proteins are down-regulated in $\mathrm{HCC}$ and their overexpression in tumor cell lines was found to suppress EMT and invasion [92].

\subsection{HNF1a}

$\mathrm{HNF} 1 \alpha$ is a homeodomain protein that plays a critical role in hepatocyte differentiation. It contributes to the expression of products central in normal hepatic functions [97] and is required for the maintenance of the differentiated state [98]. HNF1 $\alpha$, moreover, together with HNF4 $\alpha$ and HNF6, leads to the generation of functional human-induced hepatocytes (hiHeps) from fibroblasts [99] and its overexpression is necessary for the direct reprogramming of human fibroblasts to hepatocyte-like cells [100].

Extensive evidence suggested that HNF1 $\alpha$ acts as a tumor suppressor gene and that its down-regulation contributes to the development of HCC. HNF1 $\alpha$ gene was found mutated in $84 \%$ of 
cases of adenomas, including familial forms [101,102], and HNF1 $\alpha$ protein levels were found significantly reduced in moderately- and poorly-differentiated tissues from HCCs [6]. Furthermore, HNF1 $\alpha$ knock-out mice exhibit tumor-associated characteristics, such as increased proliferation of hepatocytes, leading to a dramatic liver enlargement and liver function defects [103].

Taken together, these findings suggested that restoration of HNF1 $\alpha$ functions in HCC could restrain tumor proliferation and progression. Zeng et al. recently demonstrated that the forced re-expression of HNF1 $\alpha$ in human hepatoma cell lines induces a re-establishment of hepatic differentiation through the significant induction of liver specific genes and the repression of cell proliferation. Most importantly, intratumoral HNF1 $\alpha$ transduction significantly inhibits tumor growth in mice and eradicates HCC nodules after systemic delivery [104].

HNF1 $\alpha$ is not only a promising therapeutic tool for a differentiation therapy in HCC treatment but it could be also a potent anti-EMT tool, being a strong transcriptional repressor of EMT master genes as HNF4 $\alpha$ [65]. Accordingly, suppression of HNF1 $\alpha$ in HCC cell lines triggers expression of mesenchymal and EMT master genes, overexpression of TGF $\beta$, and migration [105].

\subsection{HNF6/ONECUT1}

HNF6 represents another potential molecular tool for tumor suppression in HCC. It is essential for expression of hepatic genes, also controlling the direct expression of HNF4 $\alpha$ [106] and genes involved in glucose metabolism [107,108]. Moreover, HNF6 synergistically cooperates with HNF4 $\alpha$ and HNF1 $\alpha$ for the regulation of hepatocyte differentiation during development and in the adult. HNF6 is also a strong transcriptional activator of miR-122, establishing a positive feedback loop responsible for in vivo hepatocytes differentiation [109] that may contribute to prevent neoplastic transformation.

HNF6, as well as other LETFs, is involved both in the maintenance of the epithelial differentiation and in the active repression of EMT program through the up-regulation of p53 tumor suppressor [110]. Furthermore, it is implicated in the inhibition of HCC progression [92].

HNF6 overexpression reduced the proliferation of liver cancer cell lines [111], inhibited colony formation and cell proliferation/migration in carcinoma cells, and decreased the formation of tumors in nude mice [110]. Conversely, knockdown of HNF6 induced EMT and increased cell migration [110]. Furthermore, HNF6 has been recently shown to interfere, in vitro and in vivo, with HBV infection through the inhibition of viral gene expression and DNA replication [112].

Notably, a potential inhibitory effect of HNF6 on TGF $\beta$ signaling has recently been reported. Components of TGF $\beta$ signaling pathway were activated in HNF6 knockout mice, at least in part, through the up-regulation of TGF $\beta$ RII expression [113]. Interestingly, through the inhibition of TGF $\beta /$ activin signaling, HNF6 allows differentiation of precursor cells in hepatocytes [114]. These data, in light of what was previously observed for HNF4 $\alpha$, could indicate HNF6 as a more efficient tumor suppressor in the presence of TGF $\beta$ in the tumor microenvironment.

\section{Conclusions}

The unsuccessful therapeutic approaches for the treatment of HCCs lead to focus the attention on molecular strategies consisting of the intra-tumoral delivery of specific proteins with tumor suppressor properties. 
Recent literature data discussed above demonstrates the high potential of anti-cancer therapy based on the restoration of functions of epithelial/hepatocyte differentiation master regulators belonging to the LETF family, mainly HNF4 $\alpha$. These proteins are able to induce cellular reprogramming, coordinating extensive gene expression either through direct transcriptional regulation or by driving epigenetic changes on regulatory regions of target genes (Figure 1). LETFs, indeed, can not only induce the terminal differentiation of tumor cells (and potentially of cancer stem cells) but they can also interfere with the EMT program responsible for tumor progression. These characteristics make LETFs promising tools for molecular therapy of HCC. The challenge is now the optimization of these tools through the creation of engineered molecules to take in account the microenvironmental cues that could influence the effectiveness of this therapeutic approach. Further studies will be necessary to achieve this result.

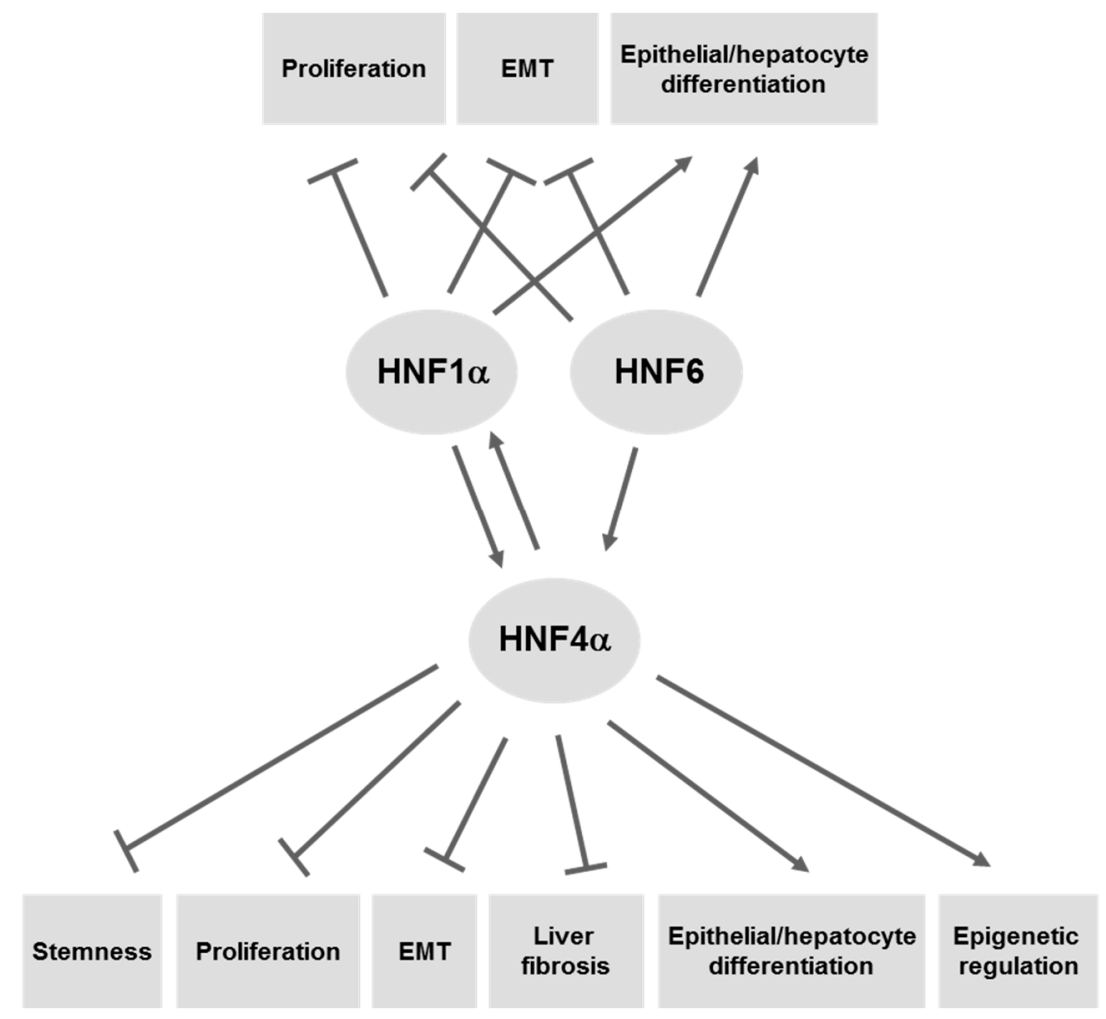

Figure 1. Tumor suppressor properties of HNF4 $\alpha$, HNF1 $\alpha$, and HNF6 in HCCs. HNFs can regulate different cell functions associated with the HCC onset and progression, through the direct transcriptional activation/repression of target genes (described in the text). The reciprocal regulation among HNFs is shown.

\section{Author Contributions}

AM and MT contributed to the design, writing and editing of the review; FB and AMC contributed to the writing and editing of the review. All authors read and approved the final manuscript.

\section{Conflicts of Interest}

The authors declare no conflict of interest. 


\section{References}

1. Farazi, P.A.; DePinho, R.A. Hepatocellular carcinoma pathogenesis: From genes to environment. Nat. Rev. Cancer 2006, 6, 674-687.

2. Spangenberg, H.C.; Thimme, R.; Blum, H.E. Targeted therapy for hepatocellular carcinoma. Nat. Rev. Gastroenterol. Hepatol. 2009, 6, 423-432.

3. Duan, F.; Lam, M.G. Delivery approaches of gene therapy in hepatocellular carcinoma. Anticancer Res. 2013, 33, 4711-4718.

4. Friemel, J.; Rechsteiner, M.; Frick, L.; Bohm, F.; Struckmann, K.; Egger, M.; Moch, H.; Heikenwalder, M.; Weber, A. Intratumor heterogeneity in hepatocellular carcinoma. Clin. Cancer Res. 2015, 21, 1951-1961.

5. Nishida, N.; Goel, A. Genetic and epigenetic signatures in human hepatocellular carcinoma: A systematic review. Curr. Genom. 2011, 12, 130-137.

6. Wang, W.; Hayashi, Y.; Ninomiya, T.; Ohta, K.; Nakabayashi, H.; Tamaoki, T.; Itoh, H. Expression of HNF-1 $\alpha$ and HNF-1 $\beta$ in various histological differentiations of hepatocellular carcinoma. J. Pathol. 1998, 184, 272-278.

7. Lazarevich, N.L.; Shavochkina, D.A.; Fleishman, D.I.; Kustova, I.F.; Morozova, O.V.; Chuchuev, E.S.; Patyutko, Y.I. Deregulation of hepatocyte nuclear factor 4 (HNF4)as a marker of epithelial tumors progression. Exp. Oncol. 2010, 32, 167-171.

8. Yumoto, Y.; Hanafusa, T.; Hada, H.; Morita, T.; Ooguchi, S.; Shinji, N.; Mitani, T.; Hamaya, K.; Koide, N.; Tsuji, T. Loss of heterozygosity and analysis of mutation of p53 in hepatocellular carcinoma. J. Gastroenterol. Hepatol. 1995, 10, 179-185.

9. Zen, K.; Yasui, K.; Nakajima, T.; Zen, Y.; Zen, K.; Gen, Y.; Mitsuyoshi, H.; Minami, M.; Mitsufuji, S.; Tanaka, S.; et al. ERK5 is a target for gene amplification at 17p11 and promotes cell growth in hepatocellular carcinoma by regulating mitotic entry. Genes Chromosom. Cancer 2009, $48,109-120$.

10. Yang, W.; Yan, H.X.; Chen, L.; Liu, Q.; He, Y.Q.; Yu, L.X.; Zhang, S.H.; Huang, D.D.; Tang, L.; Kong, X.N.; et al. Wnt/ $\beta$-catenin signaling contributes to activation of normal and tumorigenic liver progenitor cells. Cancer Res 2008, 68, 4287-4295.

11. Saito, Y.; Hibino, S.; Saito, H. Alterations of epigenetics and microRNA in hepatocellular carcinoma. Hepatol. Res. 2014, 44, 31-42.

12. Amicone, L.; Citarella, F.; Cicchini, C. Epigenetic regulation in hepatocellular carcinoma requires long noncoding RNAs. Biomed. Res. Int. 2015, 2015, doi:10.1155/2015/473942.

13. Hernandez-Vargas, H.; Lambert, M.P.; le Calvez-Kelm, F.; Gouysse, G.; McKay-Chopin, S.; Tavtigian, S.V.; Scoazec, J.Y.; Herceg, Z. Hepatocellular carcinoma displays distinct DNA methylation signatures with potential as clinical predictors. PLOS ONE 2010, 5, e9749.

14. He, C.; Xu, J.; Zhang, J.; Xie, D.; Ye, H.; Xiao, Z.; Cai, M.; Xu, K.; Zeng, Y.; Li, H.; et al. High expression of trimethylated histone $\mathrm{H} 3$ lysine 4 is associated with poor prognosis in hepatocellular carcinoma. Hum. Pathol. 2012, 43, 1425-1435.

15. Cai, M.Y.; Hou, J.H.; Rao, H.L.; Luo, R.Z.; Li, M.; Pei, X.Q.; Lin, M.C.; Guan, X.Y.; Kung, H.F.; Zeng, Y.X.; et al. High expression of H3K27me3 in human hepatocellular carcinomas correlates 
closely with vascular invasion and predicts worse prognosis in patients. Mol. Med. 2011, 17, 12-20.

16. Ladeiro, Y.; Couchy, G.; Balabaud, C.; Bioulac-Sage, P.; Pelletier, L.; Rebouissou, S.; Zucman-Rossi, J. MicroRNA profiling in hepatocellular tumors is associated with clinical features and oncogene/tumor suppressor gene mutations. Hepatology 2008, 47, 1955-1963.

17. Budhu, A.; Jia, H.L.; Forgues, M.; Liu, C.G.; Goldstein, D.; Lam, A.; Zanetti, K.A.; Ye, Q.H.; Qin, L.X.; Croce, C.M.; et al. Identification of metastasis-related microRNAs in hepatocellular carcinoma. Hepatology 2008, 47, 897-907.

18. Van Zijl, F.; Zulehner, G.; Petz, M.; Schneller, D.; Kornauth, C.; Hau, M.; Machat, G.; Grubinger, M.; Huber, H.; Mikulits, W. Epithelial-mesenchymal transition in hepatocellular carcinoma. Future Oncol. 2009, 5, 1169-1179.

19. Sugimachi, K.; Tanaka, S.; Kameyama, T.; Taguchi, K.; Aishima, S.; Shimada, M.; Sugimachi, K.; Tsuneyoshi, M. Transcriptional repressor snail and progression of human hepatocellular carcinoma. Clin. Cancer Res. 2003, 9, 2657-2664.

20. Lee, T.K.; Poon, R.T.; Yuen, A.P.; Ling, M.T.; Kwok, W.K.; Wang, X.H.; Wong, Y.C.; Guan, X.Y.; Man, K.; Chau, K.L.; et al. Twist overexpression correlates with hepatocellular carcinoma metastasis through induction of epithelial-mesenchymal transition. Clin. Cancer Res. 2006, 12, 5369-5376.

21. Li, Y.M.; Xu, S.C.; Li, J.; Han, K.Q.; Pi, H.F.; Zheng, L.; Zuo, G.H.; Huang, X.B.; Li, H.Y.; Zhao, H.Z.; et al. Epithelial-mesenchymal transition markers expressed in circulating tumor cells in hepatocellular carcinoma patients with different stages of disease. Cell Death Dis. 2013, 4, e831, doi:10.1038/cddis.2013.347.

22. Cano, A.; Perez-Moreno, M.A.; Rodrigo, I.; Locascio, A.; Blanco, M.J.; del Barrio, M.G.; Portillo, F.; Nieto, M.A. The transcription factor snail controls epithelial-mesenchymal transitions by repressing E-cadherin expression. Nat. Cell Biol. 2000, 2, 76-83.

23. Cicchini, C.; Filippini, D.; Coen, S.; Marchetti, A.; Cavallari, C.; Laudadio, I.; Spagnoli, F.M.; Alonzi, T.; Tripodi, M. Snail controls differentiation of hepatocytes by repressing HNF4 $\alpha$ expression. J. Cell. Physiol. 2006, 209, 230-238.

24. Garibaldi, F.; Cicchini, C.; Conigliaro, A.; Santangelo, L.; Cozzolino, A.M.; Grassi, G.; Marchetti, A.; Tripodi, M.; Amicone, L. An epistatic mini-circuitry between the transcription factors Snail and HNF $4 \alpha$ controls liver stem cell and hepatocyte features exhorting opposite regulation on stemnessinhibiting microRNAs. Cell Death Differ. 2011, 19, 937-946.

25. Abell, A.N.; Johnson, G.L. Implications of Mesenchymal Cells in Cancer Stem Cell Populations: Relevance to EMT. Curr. Pathobiol. Rep. 2014, 2, 21-26.

26. Ma, S.; Lee, T.K.; Zheng, B.J.; Chan, K.W.; Guan, X.Y. CD133+ HCC cancer stem cells confer chemoresistance by preferential expression of the Akt/PKB survival pathway. Oncogene 2008, 27, 1749-1758.

27. Sun, Y.F.; Xu, Y.; Yang, X.R.; Guo, W.; Zhang, X.; Qiu, S.J.; Shi, R.Y.; Hu, B.; Zhou, J.; Fan, J. Circulating stem cell-like epithelial cell adhesion molecule-positive tumor cells indicate poor prognosis of hepatocellular carcinoma after curative resection. Hepatology 2013, 57, 1458-1468.

28. Polyak, K.; Weinberg, R.A. Transitions between epithelial and mesenchymal states: Acquisition of malignant and stem cell traits. Nat. Rev. Cancer 2009, 9, 265-273. 
29. Jia, C.C.; Wang, T.T.; Liu, W.; Fu, B.S.; Hua, X.; Wang, G.Y.; Li, T.J.; Li, X.; Wu, X.Y.; Tai, Y.; et al. Cancer-associated fibroblasts from hepatocellular carcinoma promote malignant cell proliferation by HGF secretion. PLoS ONE 2013, 8, e63243.

30. Mazzocca, A.; Dituri, F.; Lupo, L.; Quaranta, M.; Antonaci, S.; Giannelli, G. Tumor-secreted lysophostatidic acid accelerates hepatocellular carcinoma progression by promoting differentiation of peritumoral fibroblasts in myofibroblasts. Hepatology 2011, 54, 920-930.

31. Shirai, Y.; Kawata, S.; Tamura, S.; Ito, N.; Tsushima, H.; Takaishi, K.; Kiso, S.; Matsuzawa, Y. Plasma transforming growth factor- $\beta 1$ in patients with hepatocellular carcinoma. Comparison with chronic liver diseases. Cancer 1994, 73, 2275-2279.

32. Ito, N.; Kawata, S.; Tamura, S.; Shirai, Y.; Kiso, S.; Tsushima, H.; Matsuzawa, Y. Positive correlation of plasma transforming growth factor- $\beta 1$ levels with tumor vascularity in hepatocellular carcinoma. Cancer Lett. 1995, 89, 45-48.

33. Lee, D.; Chung, Y.H.; Kim, J.A.; Lee, Y.S.; Lee, D.; Jang, M.K.; Kim, K.M.; Lim, Y.S.; Lee, H.C.; Lee, Y.S Transforming growth factor $\beta 1$ overexpression is closely related to invasiveness of hepatocellular carcinoma. Oncology 2012, 82, 11-18.

34. Mazzocca, A.; Fransvea, E.; Lavezzari, G.; Antonaci, S.; Giannelli, G. Inhibition of transforming growth factor $\beta$ receptor I kinase blocks hepatocellular carcinoma growth through neoangiogenesis regulation. Hepatology 2009, 50, 1140-1151.

35. Caja, L.; Bertran, E.; Campbell, J.; Fausto, N.; Fabregat, I. The transforming growth factor- $\beta$ (TGF- $\beta$ ) mediates acquisition of a mesenchymal stem cell-like phenotype in human liver cells. J. Cell Physiol. 2011, 226, 1214-1223.

36. Reichl, P.; Haider, C.; Grubinger, M.; Mikulits, W. TGF- $\beta$ in epithelial to mesenchymal transition and metastasis of liver carcinoma. Curr. Pharm. Des. 2012, 18, 4135-4147.

37. Coulouarn, C.; Factor, V.M.; Thorgeirsson, S.S. Transforming growth factor- $\beta$ gene expression signature in mouse hepatocytes predicts clinical outcome in human cancer. Hepatology 2008, 47, 2059-2067.

38. Lee, D.K.; Park, S.H.; Yi, Y.; Choi, S.G.; Lee, C.; Parks, W.T.; Cho, H.; de Caestecker, M.P.; Shaul, Y.; Roberts, A.B.; et al. The hepatitis B virus encoded oncoprotein $\mathrm{pX}$ amplifies TGF- $\beta$ family signaling through direct interaction with Smad4, potential mechanism of hepatitis B virus-induced liver fibrosis. Genes Dev. 2001, 15, 455-466.

39. Mikula, M.; Proell, V.; Fischer, A.N.; Mikulits, W. Activated hepatic stellate cells induce tumor progression of neoplastic hepatocytes in a TGF- $\beta$ dependent fashion. J. Cell Physiol. 2006, 209, $560-567$.

40. Leask, A.; Abraham, D.J. TGF- $\beta$ signaling and the fibrotic response. Faseb. J. 2004, 18, 816-827.

41. Kirmaz, C.; Terzioglu, E.; Topalak, O.; Bayrak, P.; Yilmaz, O.; Ersoz, G.; Sebik, F. Serum transforming growth factor- $\beta 1$ (TGF- $\beta 1$ ) in patients with cirrhosis, chronic hepatitis B and chronic hepatitis C. Eur. Cytokine Netw. 2004, 15, 112-116.

42. Akpolat, N.; Yahsi, S.; Godekmerdan, A.; Demirbag, K.; Yalniz, M. Relationship between serum cytokine levels and histopathological changes of liver in patients with hepatitis B. World J. Gastroenterol. 2005, 11, 3260-3263. 
43. Mazzocca, A.; Fransvea, E.; Dituri, F.; Lupo, L.; Antonaci, S.; Giannelli, G. Down-regulation of connective tissue growth factor by inhibition of transforming growth factor $\beta$ blocks the tumorstroma cross-talk and tumor progression in hepatocellular carcinoma. Hepatology 2010, 51, 523-534.

44. Mueller, S.; Sandrin, L. Liver stiffness: A novel parameter for the diagnosis of liver disease. Hepat. Med. 2010, 2, 49-67.

45. Zhao, B.; Tumaneng, K.; Guan, K.L. The Hippo pathway in organ size control, tissue regeneration and stem cell self-renewal. Nat. Cell Biol. 2011, 13, 877-883.

46. Harvey, K.F.; Zhang, X.; Thomas, D.M. The Hippo pathway and human cancer. Nat. Rev. Cancer 2013, 13, 246-257.

47. Xu, M.Z.; Yao, T.J.; Lee, N.P.; Ng, I.O.; Chan, Y.T.; Zender, L.; Lowe, S.W.; Poon, R.T.; Luk, J.M. Yes-associated protein is an independent prognostic marker in hepatocellular carcinoma. Cancer 2009, 115, 4576-4585.

48. Zender, L.; Spector, M.S.; Xue, W.; Flemming, P.; Cordon-Cardo, C.; Silke, J.; Fan, S.T.; Luk, J.M.; Wigler, M.; Hannon, G.J.; et al. Identification and validation of oncogenes in liver cancer using an integrative oncogenomic approach. Cell 2006, 125, 1253-1267.

49. Tschaharganeh, D.F.; Chen, X.; Latzko, P.; Malz, M.; Gaida, M.M.; Felix, K.; Ladu, S.; Singer, S.; Pinna, F.; Gretz, N.; et al. Yes-associated protein up-regulates Jagged-1 and activates the Notch pathway in human hepatocellular carcinoma. Gastroenterology 2013, 144, 1530-1542.

50. Fitamant, J.; Kottakis, F.; Benhamouche, S.; Tian, H.S.; Chuvin, N.; Parachoniak, C.A.; Nagle, J.M.; Perera, R.M.; Lapouge, M.; Deshpande, V.; et al. YAP Inhibition Restores Hepatocyte Differentiation in Advanced HCC, Leading to Tumor Regression. Cell Rep. 2015, doi:10.1016/ j.celrep.2015.02.027.

51. Alder, O.; Cullum, R.; Lee, S.; Kan, A.C.; Wei, W.; Yi, Y.; Garside, V.C.; Bilenky, M.; Griffith, M.; Morrissy, A.S.; et al. Hippo signaling influences HNF4A and FOXA2 enhancer switching during hepatocyte differentiation. Cell Rep. 2014, 9, 261-271.

52. Pardee, A.D.; Butterfield, L.H. Immunotherapy of hepatocellular carcinoma: Unique challenges and clinical opportunities. Oncoimmunology 2012, 1, 48-55.

53. El-Serag, H.B.; Marrero, J.A.; Rudolph, L.; Reddy, K.R. Diagnosis and treatment of hepatocellular carcinoma. Gastroenterology 2008, 134, 1752-1763.

54. Llovet, J.M.; Ricci, S.; Mazzaferro, V.; Hilgard, P.; Gane, E.; Blanc, J.F.; de Oliveira, A.C.; Santoro, A.; Raoul, J.L.; Forner, A.; et al. Sorafenib in advanced hepatocellular carcinoma. N. Engl. J. Med. 2008, 359, 378-390.

55. Lyra-Gonzalez, I.; Flores-Fong, L.E.; Gonzalez-Garcia, I.; Medina-Preciado, D.; Armendariz-Borunda, J. Adenoviral gene therapy in hepatocellular carcinoma: A review. Hepatol. Int. 2013, 7, 48-58.

56. Arbuthnot, P.B.; Bralet, M.P.; le Jossic, C.; Dedieu, J.F.; Perricaudet, M.; Brechot, C.; Ferry, N. In vitro and in vivo hepatoma cell-specific expression of a gene transferred with an adenoviral vector. Hum. Gene Ther. 1996, 7, 1503-1514.

57. Yanger, K.; Knigin, D.; Zong, Y.; Maggs, L.; Gu, G.; Akiyama, H.; Pikarsky, E.; Stanger, B.Z. Adult hepatocytes are generated by self-duplication rather than stem cell differentiation. Cell Stem. Cell 2014, 15, 340-349. 
58. Schaub, J.R.; Malato, Y.; Gormond, C.; Willenbring, H. Evidence against a stem cell origin of new hepatocytes in a common mouse model of chronic liver injury. Cell Rep. 2014, 8, 933-939.

59. Odom, D.T.; Dowell, R.D.; Jacobsen, E.S.; Nekludova, L.; Rolfe, P.A.; Danford, T.W.; Gifford, D.K.; Fraenkel, E.; Bell, G.I.; Young, R.A. Core transcriptional regulatory circuitry in human hepatocytes. Mol. Syst. Biol. 2006, 2, doi:10.1038/msb4100059.

60. Kuo, C.J.; Conley, P.B.; Chen, L.; Sladek, F.M.; Darnell, J.E., Jr.; Crabtree, G.R. A transcriptional hierarchy involved in mammalian cell-type specification. Nature 1992, 355, 457-461.

61. Kyrmizi, I.; Hatzis, P.; Katrakili, N.; Tronche, F.; Gonzalez, F.J.; Talianidis, I. Plasticity and expanding complexity of the hepatic transcription factor network during liver development. Genes Dev. 2006, 20, 2293-2305.

62. Parviz, F.; Matullo, C.; Garrison, W.D.; Savatski, L.; Adamson, J.W.; Ning, G.; Kaestner, K.H.; Rossi, J.M.; Zaret, K.S.; Duncan, S.A. Hepatocyte nuclear factor $4 \alpha$ controls the development of a hepatic epithelium and liver morphogenesis. Nat. Genet. 2003, 34, 292-296.

63. Hayhurst, G.P.; Lee, Y.H.; Lambert, G.; Ward, J.M.; Gonzalez, F.J. Hepatocyte nuclear factor $4 \alpha$ (nuclear receptor 2A1) is essential for maintenance of hepatic gene expression and lipid homeostasis. Mol. Cell Biol. 2001, 21, 1393-1403.

64. Fang, B.; Mane-Padros, D.; Bolotin, E.; Jiang, T.; Sladek, F.M. Identification of a binding motif specific to HNF4 by comparative analysis of multiple nuclear receptors. Nucleic Acids Res. 2012, 40, 5343-5356.

65. Santangelo, L.; Marchetti, A.; Cicchini, C.; Conigliaro, A.; Conti, B.; Mancone, C.; Bonzo, J.A.; Gonzalez, F.J.; Alonzi, T.; Amicone, L.; et al. The stable repression of mesenchymal program is required for hepatocyte identity: A novel role for hepatocyte nuclear factor $4 \alpha$. Hepatology 2011, 53, 2063-2074.

66. Bonzo, J.A.; Ferry, C.H.; Matsubara, T.; Kim, J.H.; Gonzalez, F.J. Suppression of hepatocyte proliferation by hepatocyte nuclear factor $4 \alpha$ in adult mice. J. Biol. Chem. 2012, 287, 7345-7356.

67. Walesky, C.; Gunewardena, S.; Terwilliger, E.F.; Edwards, G.; Borude, P.; Apte, U. Hepatocytespecific deletion of hepatocyte nuclear factor- $4 \alpha$ in adult mice results in increased hepatocyte proliferation. Am. J. Physiol. Gastrointest. Liver Physiol. 2013, 304, G26-G37.

68. Chiba, H.; Gotoh, T.; Kojima, T.; Satohisa, S.; Kikuchi, K.; Osanai, M.; Sawada, N. Hepatocyte nuclear factor (HNF)-4 $\alpha$ triggers formation of functional tight junctions and establishment of polarized epithelial morphology in F9 embryonal carcinoma cells. Exp. Cell Res. 2003, 286, 288-297.

69. Sekiya, S.; Suzuki, A. Direct conversion of mouse fibroblasts to hepatocyte-like cells by defined factors. Nature 2011, 475, 390-393.

70. Li, Z.Y.; Xi, Y.; Zhu, W.N.; Zeng, C.; Zhang, Z.Q.; Guo, Z.C.; Hao, D.L.; Liu, G.; Feng, L.; Chen, H.Z.; et al. Positive regulation of hepatic miR-122 expression by HNF4a. J. Hepatol. 2011, 55, 602-611.

71. Kutay, H.; Bai, S.; Datta, J.; Motiwala, T.; Pogribny, I.; Frankel, W.; Jacob, S.T.; Ghoshal, K. Downregulation of miR-122 in the rodent and human hepatocellular carcinomas. J. Cell Biochem. 2006, 99, 671-678.

72. Coulouarn, C.; Factor, V.M.; Andersen, J.B.; Durkin, M.E.; Thorgeirsson, S.S. Loss of miR-122 expression in liver cancer correlates with suppression of the hepatic phenotype and gain of metastatic properties. Oncogene 2009, 28, 3526-3536. 
73. Tsai, W.C.; Hsu, P.W.; Lai, T.C.; Chau, G.Y.; Lin, C.W.; Chen, C.M.; Lin, C.D.; Liao, Y.L.; Wang, J.L.; Chau, Y.P.; et al MicroRNA-122, a tumor suppressor microRNA that regulates intrahepatic metastasis of hepatocellular carcinoma. Hepatology 2009, 49, 1571-1582.

74. Wang, S.C.; Lin, X.L.; Li, J.; Zhang, T.T.; Wang, H.Y.; Shi, J.W.; Yang, S.; Zhao, W.T.; Xie, R.Y.; Wei, F.; et al. MicroRNA-122 triggers mesenchymal-epithelial transition and suppresses hepatocellular carcinoma cell motility and invasion by targeting RhoA. PLoS ONE 2014, 9, e101330.

75. Ma, L.; Liu, J.; Shen, J.; Liu, L.; Wu, J.; Li, W.; Luo, J.; Chen, Q.; Qian, C. Expression of miR-122 mediated by adenoviral vector induces apoptosis and cell cycle arrest of cancer cells. Cancer Biol. Ther. 2010, 9, 554-561.

76. Fornari, F.; Gramantieri, L.; Giovannini, C.; Veronese, A.; Ferracin, M.; Sabbioni, S.; Calin, G.A.; Grazi, G.L.; Croce, C.M.; Tavolari, S.; et al. MiR-122/cyclin G1 interaction modulates p. 53 activity and affects doxorubicin sensitivity of human hepatocarcinoma cells. Cancer Res. 2009, 69, 5761-5767.

77. Xu, Y.; Xia, F.; Ma, L.; Shan, J.; Shen, J.; Yang, Z.; Liu, J.; Cui, Y.; Bian, X.; Bie, P.; et al. MicroRNA-122 sensitizes HCC cancer cells to adriamycin and vincristine through modulating expression of MDR and inducing cell cycle arrest. Cancer Lett. 2011, 310, 160-169.

78. Hsu, S.H.; Wang, B.; Kota, J.; Yu, J.; Costinean, S.; Kutay, H.; Yu, L.; Bai, S.; La Perle, K.; Chivukula, R.R.; et al. Essential metabolic, anti-inflammatory, and anti-tumorigenic functions of miR-122 in liver. J. Clin. Invest. 2012, 122, 2871-2883.

79. Li, N.; Fu, H.; Tie, Y.; Hu, Z.; Kong, W.; Wu, Y.; Zheng, X. miR-34a inhibits migration and invasion by down-regulation of c-Met expression in human hepatocellular carcinoma cells. Cancer Lett. 2009, 275, 44-53.

80. Dhayat, S.A.; Mardin, W.A.; Kohler, G.; Bahde, R.; Vowinkel, T.; Wolters, H.; Senninger, N.; Haier, J.; Mees, S.T. The microRNA-200 family-A potential diagnostic marker in hepatocellular carcinoma? J. Surg. Oncol. 2014, 110, 430-438.

81. Hung, C.S.; Liu, H.H.; Liu, J.J.; Yeh, C.T.; Chang, T.C.; Wu, C.H.; Ho, Y.S.; Wei, P.L.; Chang, Y.J. MicroRNA-200a and -200b mediated hepatocellular carcinoma cell migration through the epithelial to mesenchymal transition markers. Ann. Surg. Oncol. 2013, 20 (Suppl. S3), S360-S368.

82. Dang, Y.; Luo, D.; Rong, M.; Chen, G. Underexpression of miR-34a in hepatocellular carcinoma and its contribution towards enhancement of proliferating inhibitory effects of agents targeting c-MET. PLOS ONE 2013, 8, e61054.

83. Li, X.J.; Ren, Z.J.; Tang, J.H. MicroRNA-34a: A potential therapeutic target in human cancer. Cell Death Dis. 2014, 5, e1327, doi:10.1038/cddis.2014.270.

84. Gougelet, A.; Sartor, C.; Bachelot, L.; Godard, C.; Marchiol, C.; Renault, G.; Tores, F.; Nitschke, P.; Cavard, C.; Terris, B.; et al. Antitumour activity of an inhibitor of miR-34a in liver cancer with $\beta$-catenin-mutations. Gut 2015, doi:10.1136/gutjnl-2014-308969..

85. Cicchini, C.; de Nonno, V.; Battistelli, C.; Cozzolino, A.M.; de Santis Puzzonia, M.; Ciafre, S.A.; Brocker, C.; Gonzalez, F.J.; Amicone, L.; Tripodi, M. Epigenetic control of EMT/MET dynamics: HNF4 $\alpha$ impacts DNMT3s through miRs-29. Biochim. Biophys. Acta 2015, 1849, 919-929.

86. Kogure, T.; Kondo, Y.; Kakazu, E.; Ninomiya, M.; Kimura, O.; Shimosegawa, T. Involvement of miRNA-29a in epigenetic regulation of transforming growth factor- $\beta$-induced epithelialmesenchymal transition in hepatocellular carcinoma. Hepatol. Res. 2014, 44, 907-919. 
87. Roderburg, C.; Urban, G.W.; Bettermann, K.; Vucur, M.; Zimmermann, H.; Schmidt, S.; Janssen, J.; Koppe, C.; Knolle, P.; Castoldi, M.; et al. Micro-RNA profiling reveals a role for miR29 in human and murine liver fibrosis. Hepatology 2011, 53, 209-218.

88. Parpart, S.; Roessler, S.; Dong, F.; Rao, V.; Takai, A.; Ji, J.; Qin, L.X.; Ye, Q.H.; Jia, H.L.; Tang, Z.Y.; et al. Modulation of miR-29 expression by $\alpha$-fetoprotein is linked to the hepatocellular carcinoma epigenome. Hepatology 2014, 60, 872-883.

89. Carmona, F.J.; Davalos, V.; Vidal, E.; Gomez, A.; Heyn, H.; Hashimoto, Y.; Vizoso, M.; Martinez-Cardus, A.; Sayols, S.; Ferreira, H.J.; et al. A comprehensive DNA methylation profile of epithelial-to-mesenchymal transition. Cancer Res. 2014, 74, 5608-5619.

90. Saito, Y.; Kanai, Y.; Sakamoto, M.; Saito, H.; Ishii, H.; Hirohashi, S. Expression of mRNA for DNA methyltransferases and methyl-CpG-binding proteins and DNA methylation status on CpG islands and pericentromeric satellite regions during human hepatocarcinogenesis. Hepatology 2001, 33, 561-568.

91. Hatziapostolou, M.; Polytarchou, C.; Aggelidou, E.; Drakaki, A.; Poultsides, G.A.; Jaeger, S.A.; Ogata, H.; Karin, M.; Struhl, K.; Hadzopoulou-Cladaras, M.; et al. An HNF4a-miRNA inflammatory feedback circuit regulates hepatocellular oncogenesis. Cell 2011, 147, 1233-1247.

92. Lazarevich, N.L.; Cheremnova, O.A.; Varga, E.V.; Ovchinnikov, D.A.; Kudrjavtseva, E.I.; Morozova, O.V.; Fleishman, D.I.; Engelhardt, N.V.; Duncan, S.A. Progression of HCC in mice is associated with a downregulation in the expression of hepatocyte nuclear factors. Hepatology 2004, 39, 1038-1047.

93. Ning, B.F.; Ding, J.; Yin, C.; Zhong, W.; Wu, K.; Zeng, X.; Yang, W.; Chen, Y.X.; Zhang, J.P.; Zhang, X.; et al. Hepatocyte nuclear factor $4 \alpha$ suppresses the development of hepatocellular carcinoma. Cancer Res. 2010, 70, 7640-7651.

94. Yue, H.Y.; Yin, C.; Hou, J.L.; Zeng, X.; Chen, Y.X.; Zhong, W.; Hu, P.F.; Deng, X.; Tan, Y.X.; Zhang, J.P.; et al. Hepatocyte nuclear factor $4 \alpha$ attenuates hepatic fibrosis in rats. Gut 2010, 59, 236-246.

95. Yin, C.; Lin, Y.; Zhang, X.; Chen, Y.X.; Zeng, X.; Yue, H.Y.; Hou, J.L.; Deng, X.; Zhang, J.P.; Han, Z.G.; et al. Differentiation therapy of hepatocellular carcinoma in mice with recombinant adenovirus carrying hepatocyte nuclear factor-4 $\alpha$ gene. Hepatology 2008, 48, 1528-1539.

96. Cozzolino, A.M.; Alonzi, T.; Santangelo, L.; Mancone, C.; Conti, B.; Steindler, C.; Musone, M.; Cicchini, C.; Tripodi, M.; Marchetti, A. TGF $\beta$ overrides HNF4 $\alpha$ tumor suppressing activity through GSK3 $\beta$ inactivation: Implication for hepatocellular carcinoma gene therapy. J. Hepatol. 2013, 58, 65-72.

97. Odom, D.T.; Zizlsperger, N.; Gordon, D.B.; Bell, G.W.; Rinaldi, N.J.; Murray, H.L.; Volkert, T.L.; Schreiber, J.; Rolfe, P.A.; Gifford, D.K.; et al. Control of pancreas and liver gene expression by HNF transcription factors. Science 2004, 303, 1378-1381.

98. Cereghini, S.; Yaniv, M.; Cortese, R. Hepatocyte dedifferentiation and extinction is accompanied by a block in the synthesis of mRNA coding for the transcription factor HNF1/LFB1. EMBO J. 1990, 9, 2257-2263.

99. Du, Y.; Wang, J.; Jia, J.; Song, N.; Xiang, C.; Xu, J.; Hou, Z.; Su, X.; Liu, B.; Jiang, T.; et al. Human hepatocytes with drug metabolic function induced from fibroblasts by lineage reprogramming. Cell Stem. Cell 2014, 14, 394-403.

100. Simeonov, K.P.; Uppal, H. Direct reprogramming of human fibroblasts to hepatocyte-like cells by synthetic modified mRNAs. PLoS ONE 2014, 9, e100134. 
101. Bluteau, O.; Jeannot, E.; Bioulac-Sage, P.; Marques, J.M.; Blanc, J.F.; Bui, H.; Beaudoin, J.C.; Franco, D.; Balabaud, C.; Laurent-Puig, P.; et al. Bi-allelic inactivation of TCF1 in hepatic adenomas. Nat. Genet. 2002, 32, 312-315.

102. Bacq, Y.; Jacquemin, E.; Balabaud, C.; Jeannot, E.; Scotto, B.; Branchereau, S.; Laurent, C.; Bourlier, P.; Pariente, D.; de Muret, A.; et al. Familial liver adenomatosis associated with hepatocyte nuclear factor $1 \alpha$ inactivation. Gastroenterology 2003, 125, 1470-1475.

103. Pontoglio, M.; Barra, J.; Hadchouel, M.; Doyen, A.; Kress, C.; Bach, J.P.; Babinet, C.; Yaniv, M. Hepatocyte nuclear factor 1 inactivation results in hepatic dysfunction, phenylketonuria, and renal Fanconi syndrome. Cell 1996, 84, 575-585.

104. Zeng, X.; Lin, Y.; Yin, C.; Zhang, X.; Ning, B.F.; Zhang, Q.; Zhang, J.P.; Qiu, L.; Qin, X.R.; Chen, Y.X.; et al. Recombinant adenovirus carrying the hepatocyte nuclear factor-1 $\alpha$ gene inhibits hepatocellular carcinoma xenograft growth in mice. Hepatology 2011, 54, 2036-2047.

105. Pelletier, L.; Rebouissou, S.; Vignjevic, D.; Bioulac-Sage, P.; Zucman-Rossi, J. HNF1 $\alpha$ inhibition triggers epithelial-mesenchymal transition in human liver cancer cell lines. BMC Cancer 2011, 11, 427, doi:10.1186/1471-2407-11-427.

106. Hatzis, P.; Talianidis, I. Regulatory mechanisms controlling human hepatocyte nuclear factor $4 \alpha$ gene expression. Mol. Cell Biol. 2001, 21, 7320-7330.

107. Tan, Y.; Adami, G.; Costa, R.H. Maintaining HNF6 expression prevents AdHNF3 $\beta$-mediated decrease in hepatic levels of Glut-2 and glycogen. Hepatology 2002, 35, 790-798.

108. Wang, M.; Tan, Y.; Costa, R.H.; Holterman, A.X. In vivo regulation of murine CYP7A1 by HNF6, a novel mechanism for diminished CYP7A1 expression in biliary obstruction. Hepatology 2004, 40, 600-608.

109. Laudadio, I.; Manfroid, I.; Achouri, Y.; Schmidt, D.; Wilson, M.D.; Cordi, S.; Thorrez, L.; Knoops, L.; Jacquemin, P.; Schuit, F.; et al. A feedback loop between the liver-enriched transcription factor network and miR-122 controls hepatocyte differentiation. Gastroenterology 2012, 142, 119-129.

110. Yuan, X.W.; Wang, D.M.; Hu, Y.; Tang, Y.N.; Shi, W.W.; Guo, X.J.; Song, J.G. Hepatocyte nuclear factor 6 suppresses the migration and invasive growth of lung cancer cells through p53 and the inhibition of epithelial-mesenchymal transition. J. Biol. Chem. 2013, 288, 31206-31216.

111. Lehner, F.; Kulik, U.; Klempnauer, J.; Borlak, J. Inhibition of the liver enriched protein FOXA2 recovers HNF6 activity in human colon carcinoma and liver hepatoma cells. PLoS ONE 2010, 5, e13344.

112. Hao, R.; He, J.; Liu, X.; Gao, G.; Liu, D.; Cui, L.; Yu, G.; Yu, W.; Chen, Y.; Guo, D. Inhibition of hepatitis B virus gene expression and replication by hepatocyte nuclear factor 6. J. Virol. 2015, 89, 4345-4355.

113. Plumb-Rudewiez, N.; Clotman, F.; Strick-Marchand, H.; Pierreux, C.E.; Weiss, M.C.; Rousseau, G.G.; Lemaigre, F.P. Transcription factor HNF-6/OC-1 inhibits the stimulation of the HNF-3 $\alpha$ /Foxal gene by TGF- $\beta$ in mouse liver. Hepatology 2004, 40, 1266-1274.

114. Clotman, F.; Jacquemin, P.; Plumb-Rudewiez, N.; Pierreux, C.E.; Van der Smissen, P.; Dietz, H.C.; Courtoy, P.J.; Rousseau, G.G.; Lemaigre, F.P. Control of liver cell fate decision by a gradient of TGF $\beta$ signaling modulated by Onecut transcription factors. Genes Dev. 2005, 19, 1849-1854.

(C) 2015 by the authors; licensee MDPI, Basel, Switzerland. This article is an open access article distributed under the terms and conditions of the Creative Commons Attribution license (http://creativecommons.org/licenses/by/4.0/). 